\title{
A functional candidate screen for coeliac disease genes
}

\author{
Christine R Curley ${ }^{1,4}$, Alienke J Monsuur ${ }^{2,4}$, Martin C Wapenaar ${ }^{2}$, John D Rioux ${ }^{1,3}$ and \\ Cisca Wijmenga*,2
}

\begin{abstract}
${ }^{1}$ The Broad Institute, Massachusetts Institute of Technology and Harvard University, Cambridge, MA, USA; ${ }^{2}$ Complex Genetics Section, DBG-Department of Medical Genetics, University Medical Centre Utrecht, Utrecht, The Netherlands;

${ }^{3}$ Université de Montreal and the Montreal Heart Institute/Institut de Cardiologie de Montreal, Montreal, Quebec, Canada
\end{abstract}

It is increasingly evident that different inflammatory disorders show some overlap in their pathological features, concurrence in families and individuals, and shared genetic factors. This might also be true for coeliac disease, a chronic inflammatory disorder of the gastrointestinal system, which shares two linkage regions with inflammatory bowel disease: on chromosome 5q31 (CELIAC2 and IBD5) and 19p13 (CELIAC4 and IBD6). We hypothesised that these regions contain genes that contribute to susceptibility to both disorders. The overlapping 5 q31 region contains only five positional candidate genes, whereas the overlapping 19p13 region has 141 genes. As the common disease gene probably plays a role in inflammation, we selected five functional candidate genes from the $19 \mathrm{p} 13$ region. We studied these 10 positional and functional candidate genes in our Dutch coeliac disease cohort using $\mathbf{4 4}$ haplotype tagging single-nucleotide polymorphisms. Two genes from 19p13 showed a small effect on familial clustering: the cytochrome P450 F3 gene CYP4F3 ( $P_{\text {nominal }} 0.0375$, odds ratio (OR) 1.77 ) and CYP4F2 ( $P_{\text {nominal }} 0.013$, OR 1.33). CYP4F3 and CYP4F2 catalyse the inactivation of leukotriene B4 (LTB4), a potent mediator of inflammation responsible for recruitment and activation of neutrophils. The genetic association of LTB4regulating gene variants connects the innate immune response of neutrophil mobilisation with that of the established Th1 adaptive immunity present in coeliac disease patients. The findings in coeliac disease need to be replicated. Expanding genetic association studies of these cytochrome genes to other inflammatory conditions should reveal whether their causative influence extends beyond coeliac disease.

European Journal of Human Genetics (2006) 14, 1215-1222. doi:10.1038/sj.ejhg.5201687; published online 12 July 2006

Keywords: coeliac disease; inflammatory bowel disease; MYO9B; inflammation; candidate gene study; IBD5

\section{Introduction}

Coeliac disease is a chronic disease characterised by an inflammatory response in the gastrointestinal tract and an

\footnotetext{
*Correspondence: Professor C Wijmenga, Complex Genetics Section, Stratenum 2.117, DBG-Department of Biomedical Genetics, University Medical Centre Utrecht, PO Box 85060, 3508 AB Utrecht, The Netherlands. Tel: + 3130253 8427; Fax: + 3130253 8479;

E-mail: t.n.wijmenga@med.uu.nl

${ }^{4}$ These authors have contributed equally to this work.

Received 14 December 2005; revised 18 May 2006; accepted 30 May 2006; published online 12 July 2006
}

impaired intestinal epithelial barrier. ${ }^{1}$ It is a complex genetic disorder, involving multiple genetic variants. Genetic studies on coeliac disease patients indicate that multiple chromosomal regions predispose to disease susceptibility, confirming the suggestion that common genes contribute to this disorder. Two of the coeliac disease loci, CELIAC2 on chromosome 5q23-q33 and CELIAC4 on 19p13.1, ${ }^{2,3}$ coincide with linkage regions for inflammatory bowel disease (IBD), ${ }^{4,5}$ giving rise to the hypothesis of common disease susceptibility. The IBD5 and IBD6 loci on 5q31 and 19p13.1, respectively, are among the most significant and consistently 
replicated IBD loci. ${ }^{6,7}$ There is ample evidence that (auto)immune-related disorders share some of their genetic susceptibility factors, the best examples being variations in the CTLA-4 gene $^{8}$ and PTPN22, ${ }^{9-11}$ both of which help regulate $\mathrm{T}$-cell responsiveness.

IBD, clinically classified as Crohn's disease and ulcerative colitis, also shows a chronic inflammation of the gastrointestinal tract. ${ }^{6}$ Coeliac disease and IBD co-occur in families and patients, with an approximately five-fold increased prevalence of IBD in coeliac disease patients, ${ }^{12-15}$ further suggesting common pathophysiological mechanisms for both diseases.

The sharing of the linkage regions, the concurrence in patients and the pathological commonalities between coeliac disease and IBD led us to hypothesise that genes on chromosomes 5q31 and 19p13.1 might be associated with susceptibility for both disorders, most probably by influencing inflammation in the gut. The CELIAC2 locus on 5 q23-q33 overlaps with a $250 \mathrm{~kb}$ haplotype on $5 \mathrm{q} 31$ associated with Crohn's disease (IBD5). ${ }^{16}$ The implicated haplotype contains five genes (P4HA2, IRF1, SLC22A5/ OCTN2, SLC22A4/OCTN1, PDLIM3) (see Table 1), all of which are positional candidate genes for coeliac disease pathogenesis. The CELIAC4 locus ranging from 15.38 to $21.08 \mathrm{Mb}$ (99\% confidence interval (CI), Ensembl version 35) lies completely within the IBD6 locus, which spans a large part of chromosome 19p. Of the 141 genes in the overlapping region, five are known to be involved in inflammation and were considered as functional candidate genes: CYP4F3, CYP4F2, HSH2D, IL12RB1 and IFI3O (see Table 1). A complementary approach to identifying the susceptibility gene for coeliac disease in the chromosome 19 region involves fine-mapping of the region. We simultaneously undertook such a strategy, which led to

Table 1 Overview of the 10 positional and functional candidate genes studied in relation to the overlapping regions in coeliac disease and IBD

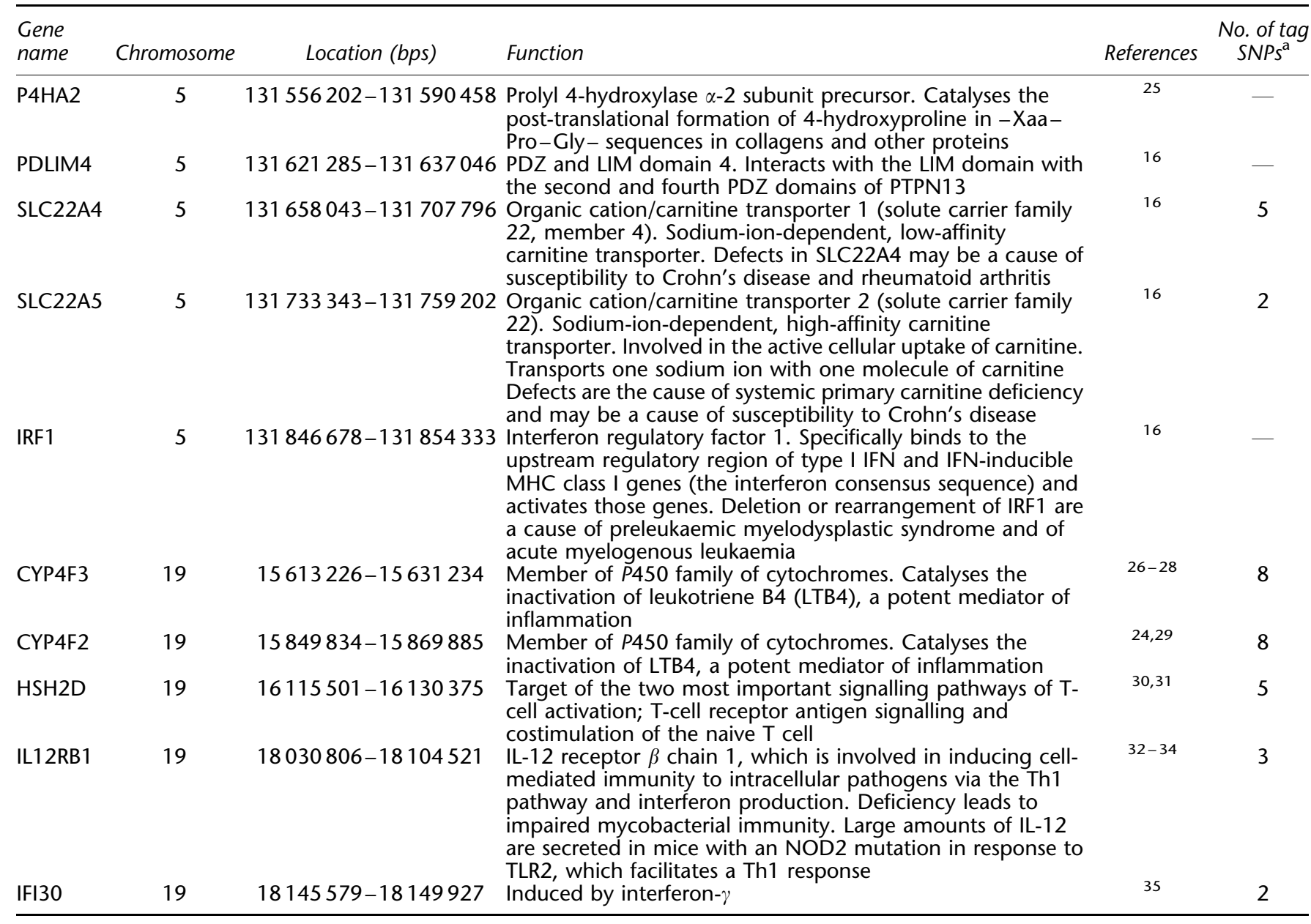

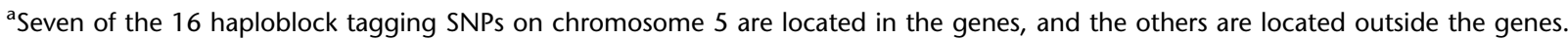


the identification of the myosin IXB gene (MYO9B) as a susceptibility gene for coeliac disease. ${ }^{17}$ The odds ratio (OR) for this gene is lower than the expected OR for the CELIAC4 locus, leaving room for another susceptibility gene in this locus. In this study, we report our association findings of the five positional candidate genes comprising the $250 \mathrm{~kb}$ haplotype on $5 \mathrm{q} 31$ and the five functional candidate genes from 19p13.1; all were tested using a haplotype block tag approach for association with coeliac disease in a cohort of Dutch patients.

\section{Materials and methods Samples}

A case-control cohort consisting of 309 independent coeliac disease patients and 358 independent controls, all of Dutch Caucasian origin, was used for the genetic association study. Patients were diagnosed according to the ESPGHAN criteria and approximately 93\% of the patients were HLA-DQ2 positive. We included for this study only coeliac disease patients with a biopsy-proven Marsh III lesion, as described by Van Belzen et al. ${ }^{3}$ Blood samples were collected and DNA was isolated according to the standard laboratory procedures. ${ }^{3}$ The study was approved by the Medical Ethics Committee of the University Medical Centre in Utrecht and informed consent was obtained from all individuals.

\section{Candidate gene and single-nucleotide polymorphism (SNP) selection}

A total of 16 haplotype tagging SNPs were selected from the 5 q31 region, as described before. ${ }^{16}$ We observed comparable haplotypes to the ones published by Rioux et al. ${ }^{16} \mathrm{We}$ also selected five functional candidate genes located in the overlapping CELIAC4 and IBD6 locus on chromosome 19 for this study, based on their known function, expression studies and HapMap SNP coverage. We selected SNPs based on block-tagging ability, validation status, allele frequency and SNP density. Previous performance rating (genotyping $>90 \%$ ) from the IBD cohort typing, on the Sequenom platform, was also taken into account. Haplotype tagging SNPs were selected on the basis of HapMap data as of September 2004 (www.hapmap.org) using Haploview to determine the haplotype tagging SNPs. These SNPs were selected at an early stage of the HapMap project when there was less information than available today. If tag SNPs could not be determined from HapMap data, Supplemental data sets (Programs for Genomic Applications (PGA) and previous haplotype analyses by our group (JD Rioux, personal communication)) were used for haplotype tagging SNP selection using Haploview as described above. Supplementary Table 1 lists the selected tagging SNPs per gene that were tested on the coeliac disease cohort.

\section{Genotyping}

Genomic DNA extracted from whole-blood samples was used. Genotyping assays were designed using the Sequenom Assay Design program and genotypes were obtained using the Sequenom Mass Array system at the Broad Institute of MIT and Harvard as described by Gabriel et al. ${ }^{18}$ Genotyping data was analysed for Hardy-Weinberg equilibrium and allele frequency. The quality control criteria used to determine if genotyping results were successful were: a minimum of $75 \%$ genotyping success for each SNP, Hardy-Weinberg equilibrium values $>0.01$ and observed heterozygosity $>0.5 \%$. Of 44 SNPs tested in the region, 42 SNPs passed the above criteria (one was monomorphic and the other failed owing to HardyWeinberg errors).

\section{Statistical analysis}

Allele and haplotype counts in cases versus controls were analysed for association. A single-marker and multimarker association study for each gene in the case-control cohort was conducted by a standard $\chi^{2}$ test $(2 \times 2$ contingency table). Haplotypes were constructed using Haploview for the unrelated cases and for the control cohorts separately. ${ }^{19}$ OR represents maximum-likelihood estimate of odds ratio, and the corresponding 95\% CI was approximated using Woolf's method.

The relative risk for coeliac disease associated with the CELIAC4 locus base on the linkage data is calculated to be 2.3. ${ }^{3}$ The OR associated with MYO9B heterozygosity is estimated to be 1.6 and homozygosity $2.3 .{ }^{17}$ We calculated the power for this study based on a relative risk of 1.7, which gives us more than $75 \%$ power to detect a disease variant with minor allele frequencies ranging from 0.1 to 0.3 , assuming a dominant inheritance, a disease prevalence of 0.1 , a $D^{\prime}$ of 1 and an equal frequency of the tested SNP and the high-risk variant.

\section{Results}

Coeliac disease and IBD share linkage regions on chromosome 5q23-q33 (CELIAC2 and IBD5) and 19p13 (CELIAC4 and IBD6). We performed association studies on 10 positional and functional candidate genes to search for association with genes that might play a primary role in both disorders. Forty-four SNPs were selected to tag the haplotype blocks, thereby excluding redundant typing, and were genotyped in a cohort of 309 independent Dutch coeliac disease cases and 358 Dutch controls. Two tag SNPs failed to pass our quality control standards.

In the chromosome 5 region, one SNP showed association $\left(P_{\text {nominal }}<0.05\right)$ : rs7705826 located in SLC22A5 ( $P_{\text {nominal }} 0.033$, OR $1.39,95 \%$ CI 1.03-1.88). Owing to the high linkage disequilibrium (LD) in the region, we would have expected to find more than one SNP from this region to be associated. Therefore, this observation is 
probably false positive also because this SNP deviates from Hardy-Weinberg equilibrium in the control population.

In the chromosome 19 region, four SNPs showed single SNP association, two of which were located in CYP4F2 and two in CYP4F3 (Table 2, Figure 1). These genes are located head-to-head $218 \mathrm{~kb}$ apart. SNPs rs7252046 ( $P_{\text {nominal }}$ 0.0427, OR 1.28, 95\% CI 1.01-1.61) and rs3093156 ( $P_{\text {nominal }} 0.013$, OR 1.33, 95\% CI 1.06-1.66) showed association in CYP4F2, and SNPs rs1290622 ( $P_{\text {nominal }}$ 0.0447, OR 1.58, 95\% CI 1.01-2.48) and rs1290625 ( $P_{\text {nominal }} 0.0375$, OR $1.77,95 \%$ CI $\left.1.03-3.05\right)$ in $C Y P 4 F 3$. Heterozygotes for the most associated SNP (rs3093156 in CYP4F2) have a 1.6 times higher risk of coeliac disease ( $P_{\text {nominal }} 0.021,95 \%$ CI $\left.1.07-2.4\right)$, whereas in homozygotes the risk increases to 1.84 ( $P_{\text {nominal }} 0.01,95 \%$ CI $1.15-2.93$ ). The results obtained for these genes are independent as the $r^{2}$ between the SNPs in the genes is $<0.06$. Haplotype analyses of each of the two SNPs in the CYP4F2 and CYP4F3 genes are shown in Table 3 . The other seven genes (IRF1, SLC22A4/OCTN1, PDLIM3, P4HA2, IF130, IL12RB1 and $H S H 2 D)$ showed no association.

\section{Discussion}

In the last decade, much research has been devoted to elucidating the genetic basis of complex traits such as coeliac disease. Although increasingly successful, this work has been complicated by the fact that multiple genes can be associated with a trait, but each has insufficient impact to account for the total genetic susceptibility of the disease under study. Given the extent of linkage regions and the large number of genes they usually encompass, it can be a daunting task to select the most plausible candidate gene, particularly when little or no knowledge is available on gene function or the biological process perturbed. Both the coeliac disease loci on chromosome 5q23-q33 and 19p13.1 coincide with linkage regions for IBD. We therefore hypothesised that genes related to biological processes common to both disorders would make excellent functional candidates.

In this study, we observed nominal association to a single SNP located in SLC22A5 on chromosome 5. Although it is not clear which of the five genes in this region really confer susceptibility to Crohn's disease, ${ }^{16}$ changes in the SLC22A4 and SLC22A5 have been observed in relation to Crohn's disease, ${ }^{20}$ which potentially have a functional relevance. The effect of the association in coeliac disease is quite modest compared to the original findings in Crohn's disease. Furthermore, the other SNPs that we tested in the region show no association despite being in nearcomplete LD. Given these results, we feel that the most parsimonious explanation is that this association of SLC22A5 to celiac disease is a false positive, but this will require confirmation by independent groups.
Recently, a study has been published investigating 56 candidate genes from chromosome 19 for their involvement in IBD. ${ }^{21}$ All but one (CYP4F2) of the genes included in this study overlap with the genes published by TelloRuiz et al. ${ }^{21}$ We observed association to the cytochrome genes, CYP4F2 and CYP4F3, in a cohort of Dutch coeliac disease patients. Although the genes are juxtaposed on chromosome 19, the observed association signals are independent as there is hardly any LD between them (maximum $r^{2}$ between the associated SNPs of the two genes is $<0.06)$. The relative risk associated to each of the two genes ranges from 1.6 to 1.8 , which is insufficient to fully explain the linkage result observed earlier. ${ }^{3}$ It is interesting that variants in the myosin IXB gene $(M Y O 9 B)$, located approximately $1.2 \mathrm{Mb}$ proximal to $C Y P 4 F 2$, have recently been shown to be associated with increased risk $(\mathrm{OR}=1.7)$ to coeliac disease. ${ }^{17}$ The association found in the CYP4F2 and $C Y P 4 F 3$ genes is not owing to long-range $\mathrm{LD}$ between these genes and MYO9B (maximum $r^{2}<0.0044$ ). Although the observation with the CYP4F2 and CYP4F3 genes has not been corrected for multiple testing and needs to be independently replicated, it is tempting to speculate that the original strong linkage signal on $19 \mathrm{p} 13.1^{3}$ resulted from the presence of multiple susceptibility genes.

If we look at their function, the involvement of these two CYP4F genes is intriguing. Both CYP4F isoforms are involved in the oxidative degradation of leukotriene B4 (LTB4), the arachidonic acid-derived lipid inflammatory mediator responsible for the recruitment and activation of neutrophils. The genetic association of LTB4-regulating gene variants connects the innate immune response of neutrophil mobilisation with that of the established Th1 adaptive immunity present in coeliac disease. These genetic variants may influence neutrophil migration and thus create an environment in the mucosa that contributes to coeliac disease pathogenesis. It has been reported that activated neutrophils have an effect on epithelial tight junctions that results in enhanced permeability ${ }^{22}$ in the intestine, which could facilitate the influx of various commensals from the lumen leading to the recruitment of even more phagocytic neutrophils. This self-sustaining cycle of barrier impairment could also enable gluten to enter the lamina propria, where it could be presented to resident $\mathrm{CD}^{+} \mathrm{T}$ cells to evoke the Th1 response. In turn, activation of the Th1 immune pathway would further undermine barrier integrity through the release of interferon- $\gamma \cdot{ }^{23}$ In a parallel gene expression study, we observed increased neutrophil numbers not only in untreated coeliac patients but also in patients in complete remission, probably reflecting a genetic impairment of the epithelial barrier. $^{25}$ This observation is in line with the recently identified $M Y O 9 B$ gene, which is expected to confer genetic susceptibility to coeliac disease pathogenesis by also affecting the intestinal barrier. ${ }^{17} \mathrm{~A}$ more detailed assessment of the contribution of CYP4F2 and CYP4F3 variants 
Table 2 Association results for the SNPs that were polymorphic and in Hardy-Weinberg equilibrium (HWE)

\begin{tabular}{|c|c|c|c|c|c|c|c|c|c|c|c|c|c|}
\hline \multirow[b]{2}{*}{ Gene } & \multirow[b]{2}{*}{ rs number } & \multirow[b]{2}{*}{ Chromosome } & \multirow[b]{2}{*}{$\begin{array}{l}\text { Base pair } \\
\text { position }\end{array}$} & \multirow[b]{2}{*}{ MAJ allele ${ }^{\mathrm{a}}$} & \multirow[b]{2}{*}{$\begin{array}{c}\text { HWE P-value } \\
\text { controls }\end{array}$} & \multirow[b]{2}{*}{$\begin{array}{c}\text { HWE } P \text { - } \\
\text { value cases }\end{array}$} & \multicolumn{2}{|c|}{ Frequency $^{\mathrm{a}}$} & \multicolumn{2}{|c|}{ Allele counts ${ }^{\mathrm{b}}$} & \multirow[b]{2}{*}{$\chi^{2}$} & \multirow[b]{2}{*}{ P-value } & \multirow[b]{2}{*}{ OR $(95 \% \mathrm{Cl})^{\mathrm{C}}$} \\
\hline & & & & & & & Case & Control & Case & Control & & & \\
\hline SLC22A4 & rs7705189 & 5 & 131651257 & $\mathrm{~T}, \mathrm{~T}$ & 0.227 & 0.802 & 0.552 & 0.532 & $328: 266$ & $367: 323$ & 0.530 & 0.467 & \\
\hline SLC22A4 & rs162887 & 5 & 131657064 & $C, C$ & 0.417 & 0.737 & 0.690 & 0.686 & $422: 190$ & $479: 219$ & 0.016 & 0.898 & \\
\hline SLC22A4 & IGR3081ms1 & 5 & 131658751 & $\mathrm{~T}, \mathrm{~T}$ & 0.043 & 0.764 & 0.572 & 0.537 & $348: 260$ & $382: 330$ & 1.705 & 0.192 & \\
\hline SLC22A4 & IGR3066ms1 & 5 & 131666223 & A, A & 0.217 & 0.436 & 0.528 & 0.520 & $319: 285$ & $366: 338$ & 0.089 & 0.766 & \\
\hline SLC22A4 & rs27060 & 5 & 131679710 & $A, A$ & 0.392 & 1.000 & 0.606 & 0.615 & $367: 239$ & $429: 269$ & 0.111 & 0.740 & \\
\hline - & rs4705938 & 5 & 131721976 & A, A & 0.176 & 0.638 & 0.545 & 0.520 & $325: 271$ & $361: 333$ & 0.813 & 0.367 & \\
\hline - & rs671473 & 5 & 131736434 & $G, G$ & 0.449 & 0.523 & 0.685 & 0.686 & 419:193 & $480: 220$ & 0.002 & 0.967 & \\
\hline - & rs 274567 & 5 & 131742308 & $G, G$ & 1.000 & 0.340 & 0.562 & 0.543 & $326: 254$ & $357: 301$ & 0.475 & 0.491 & \\
\hline SLC22A5 & rs17622208 & 5 & 131744949 & C, C & 0.228 & 0.469 & 0.542 & 0.514 & $323: 273$ & $356: 336$ & 0.971 & 0.324 & \\
\hline SLC22A5 & rs7705826 & 5 & 131760355 & $C, C$ & 0.022 & 0.739 & 0.822 & 0.865 & 498:108 & 595:93 & 4.550 & 0.033 & $1.39(1.03-1.88)$ \\
\hline - & rs11739135 & 5 & 131761296 & $C, C$ & 0.272 & 0.992 & 0.610 & 0.567 & $376: 240$ & $397: 303$ & 2.528 & 0.112 & \\
\hline - & rs13179841 & 5 & 131770719 & $G, G$ & 0.504 & 0.502 & 0.934 & 0.938 & $564: 40$ & $655: 43$ & 0.116 & 0.734 & \\
\hline - & rs4475253 & 5 & 131804405 & $\mathrm{~T}, \mathrm{~T}$ & 0.867 & 0.588 & 0.698 & 0.706 & $420: 182$ & $490: 204$ & 0.108 & 0.742 & \\
\hline - & rs4705950 & 5 & 131821185 & $G, G$ & 0.095 & 1.000 & 0.569 & 0.552 & $340: 258$ & $384: 312$ & 0.370 & 0.543 & \\
\hline - & rs6894249 & 5 & 131825446 & $\mathrm{~T}, \mathrm{~T}$ & 0.303 & 1.000 & 0.613 & 0.649 & $373: 235$ & $454: 246$ & 1.723 & 0.189 & \\
\hline - & rs2248116 & 5 & 131832246 & $\mathrm{~T}, \mathrm{~T}$ & 0.225 & 0.896 & 0.577 & 0.554 & $352: 258$ & $391: 315$ & 0.718 & 0.397 & \\
\hline CYP4F3 & rs4807964 & 19 & 15609827 & $G, G$ & 1.000 & 0.231 & 0.841 & 0.811 & $461: 87$ & 555:129 & 1.873 & 0.171 & \\
\hline CYP4F3 & rs1290617 & 19 & 15612897 & $\mathrm{~T}, \mathrm{~T}$ & 0.233 & 0.789 & 0.591 & 0.623 & $357: 247$ & $441: 267$ & 1.385 & 0.239 & \\
\hline CYP4F3 & rs1290618 & 19 & 15613137 & $C, C$ & 0.379 & 0.075 & 0.770 & 0.758 & $442: 132$ & $532: 170$ & 0.260 & 0.610 & \\
\hline CYP4F3 & rs1290622 & 19 & 15614423 & C, C & 0.838 & 0.860 & 0.947 & 0.918 & $551: 31$ & $652: 58$ & 4.029 & 0.045 & $1.58(1.01-2.48)$ \\
\hline CYP4F3 & rs1290625 & 19 & 15618156 & G, G & 0.650 & 0.122 & 0.940 & 0.965 & $521: 33$ & $643: 23$ & 4.327 & 0.038 & $1.77(1.03-3.05)$ \\
\hline CYP4F3 & rs1290626 & 19 & 15618927 & C, C & 1.000 & 0.912 & 0.587 & 0.577 & $338: 238$ & 411:301 & 0.120 & 0.730 & \\
\hline CYP4F3 & rs1543284 & 19 & 15637785 & $G, G$ & 0.906 & 1.000 & 0.575 & 0.572 & $354: 262$ & $406: 304$ & 0.011 & 0.917 & \\
\hline CYP4F3 & rs1543286 & 19 & 15637945 & C, C & 0.987 & 0.976 & 0.503 & 0.524 & $289: 285$ & $373: 339$ & 0.529 & 0.467 & \\
\hline CYP4F2 & rs2189784 & 19 & 15820200 & $G, G$ & 0.187 & 0.834 & 0.610 & 0.613 & $376: 240$ & $429: 271$ & 0.008 & 0.927 & \\
\hline CYP4F2 & rs2079288 & 19 & 15825203 & $\mathrm{~T}, \mathrm{~T}$ & 0.918 & 0.970 & 0.755 & 0.762 & $447: 145$ & $538: 168$ & 0.086 & 0.770 & \\
\hline CYP4F2 & rs7252046 & 19 & 15832473 & $\mathrm{~T}, \mathrm{~T}$ & 1.000 & 0.217 & 0.708 & 0.655 & 415:171 & $468: 246$ & 4.107 & 0.043 & $1.28(1.01-1.61)$ \\
\hline CYP4F2 & rs12610189 & 19 & 15839641 & $\mathrm{~T}, \mathrm{~T}$ & 0.669 & 0.568 & 0.635 & 0.664 & $352: 202$ & $426: 216$ & 1.038 & 0.308 & \\
\hline CYP4F2 & rs2108622 & 19 & 15851431 & $C, C$ & 0.054 & 0.660 & 0.712 & 0.732 & $430: 174$ & 521:191 & 0.641 & 0.424 & \\
\hline CYP4F2 & rs3093156 & 19 & 15861609 & $\mathrm{~T}, \mathrm{~A}$ & 0.850 & 0.124 & 0.544 & 0.527 & $309: 259$ & $355: 319$ & 6.167 & 0.013 & $1.33(1.06-1.66)$ \\
\hline CYP4F2 & rs3093135 & 19 & 15865371 & $\mathrm{~T}, \mathrm{~T}$ & 0.452 & 0.326 & 0.844 & 0.880 & $449: 83$ & $523: 71$ & 3.165 & 0.075 & \\
\hline CYP4F2 & rs3761014 & 19 & 15872763 & C, C & 0.382 & 0.401 & 0.832 & 0.844 & $506: 102$ & $604: 112$ & 0.312 & 0.577 & \\
\hline $\mathrm{HSH} 2$ & rs 2032882 & 19 & 16105817 & $A, A$ & 0.151 & 0.639 & 0.910 & 0.879 & $453: 45$ & $564: 78$ & 2.824 & 0.093 & \\
\hline $\mathrm{HSH} 2$ & rs444053 & 19 & 16113072 & $C, C$ & 0.531 & 1.000 & 0.719 & 0.725 & $433: 169$ & $516: 196$ & 0.048 & 0.826 & \\
\hline $\mathrm{HSH} 2$ & rs285290 & 19 & 16120460 & C, C & 0.535 & 0.541 & 0.832 & 0.848 & $476: 96$ & 599:107 & 0.626 & 0.429 & \\
\hline $\mathrm{HSH} 2$ & rs 2258476 & 19 & 16126017 & $A, A$ & 0.403 & 0.599 & 0.833 & 0.829 & 498:100 & $585: 121$ & 0.040 & 0.842 & \\
\hline $\mathrm{HSH} 2$ & rs681059 & 19 & 16130507 & A, A & 1.000 & 0.686 & 0.717 & 0.721 & $433: 171$ & $516: 200$ & 0.023 & 0.879 & \\
\hline IL12RB1 & rs 404733 & 19 & 18030997 & A, A & 0.585 & 0.850 & 0.513 & 0.513 & $311: 295$ & $363: 345$ & 0.000 & 0.986 & \\
\hline IL12RB1 & rs375947 & 19 & 18041451 & A, A & 0.675 & 0.454 & 0.686 & 0.674 & $424: 194$ & $473: 229$ & 0.228 & 0.633 & \\
\hline IL12RB1 & rs436857 & 19 & 18058635 & $\mathrm{G}, \mathrm{G}$ & 0.476 & 0.525 & 0.798 & 0.803 & $487: 123$ & $565: 139$ & 0.036 & 0.849 & \\
\hline IFI30 & rs273266 & 19 & 18144501 & $\mathrm{~T}, \mathrm{~T}$ & 0.932 & 0.213 & 0.787 & 0.772 & $455: 123$ & 545:161 & 0.429 & 0.513 & \\
\hline IFI30 & rs7125 & 19 & 18149069 & $A, G$ & 0.670 & 0.160 & 0.502 & 0.531 & $306: 304$ & $360: 318$ & 1.367 & 0.242 & \\
\hline
\end{tabular}

${ }^{a}$ Major allele in cases and controls, which may be the opposite allele.

${ }^{b}$ Actual allele counts for cases and controls; the major allele is shown first.

'Odds ratio (OR) calculated using the not-associated allele as reference. 
a
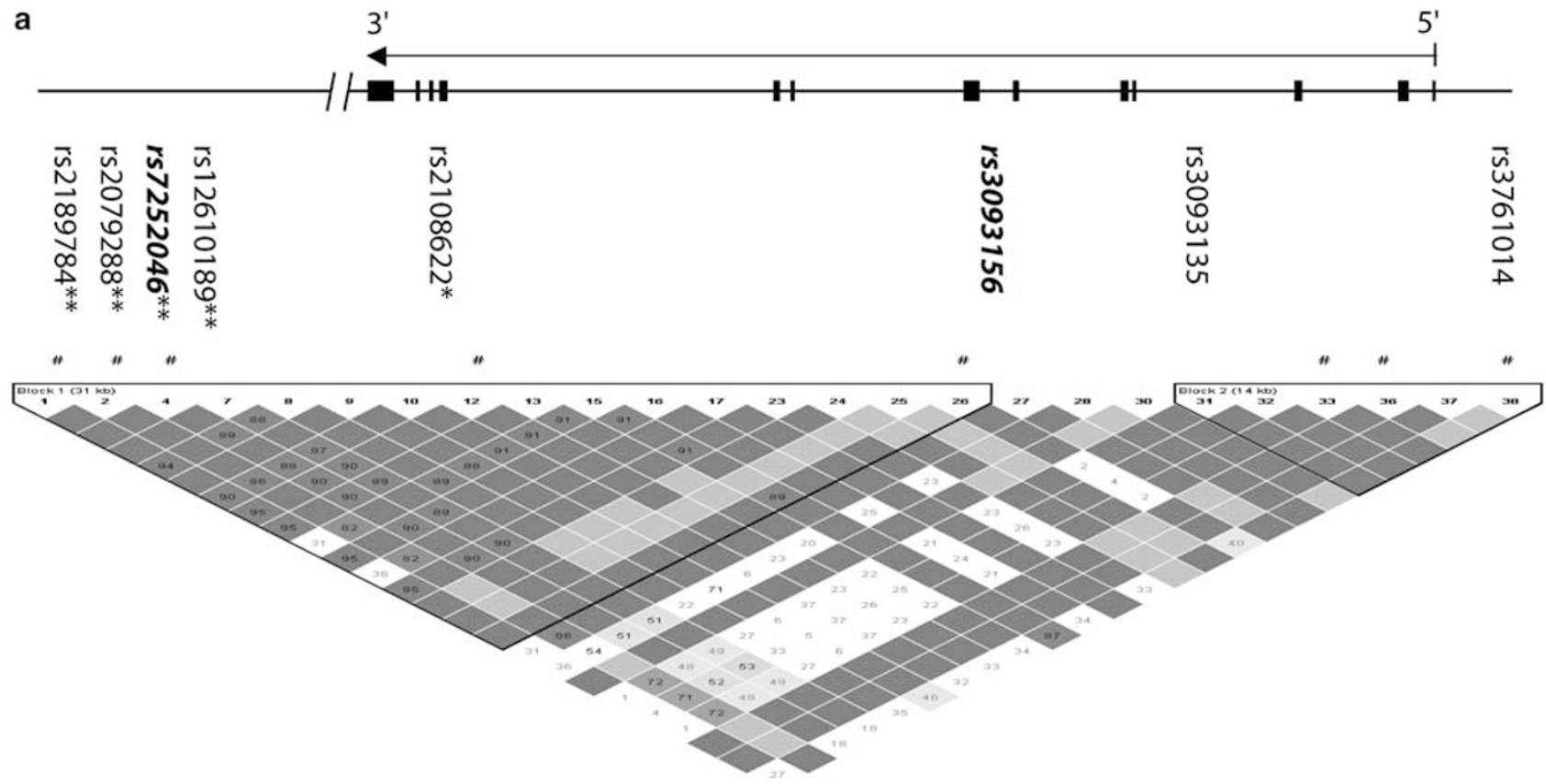

b
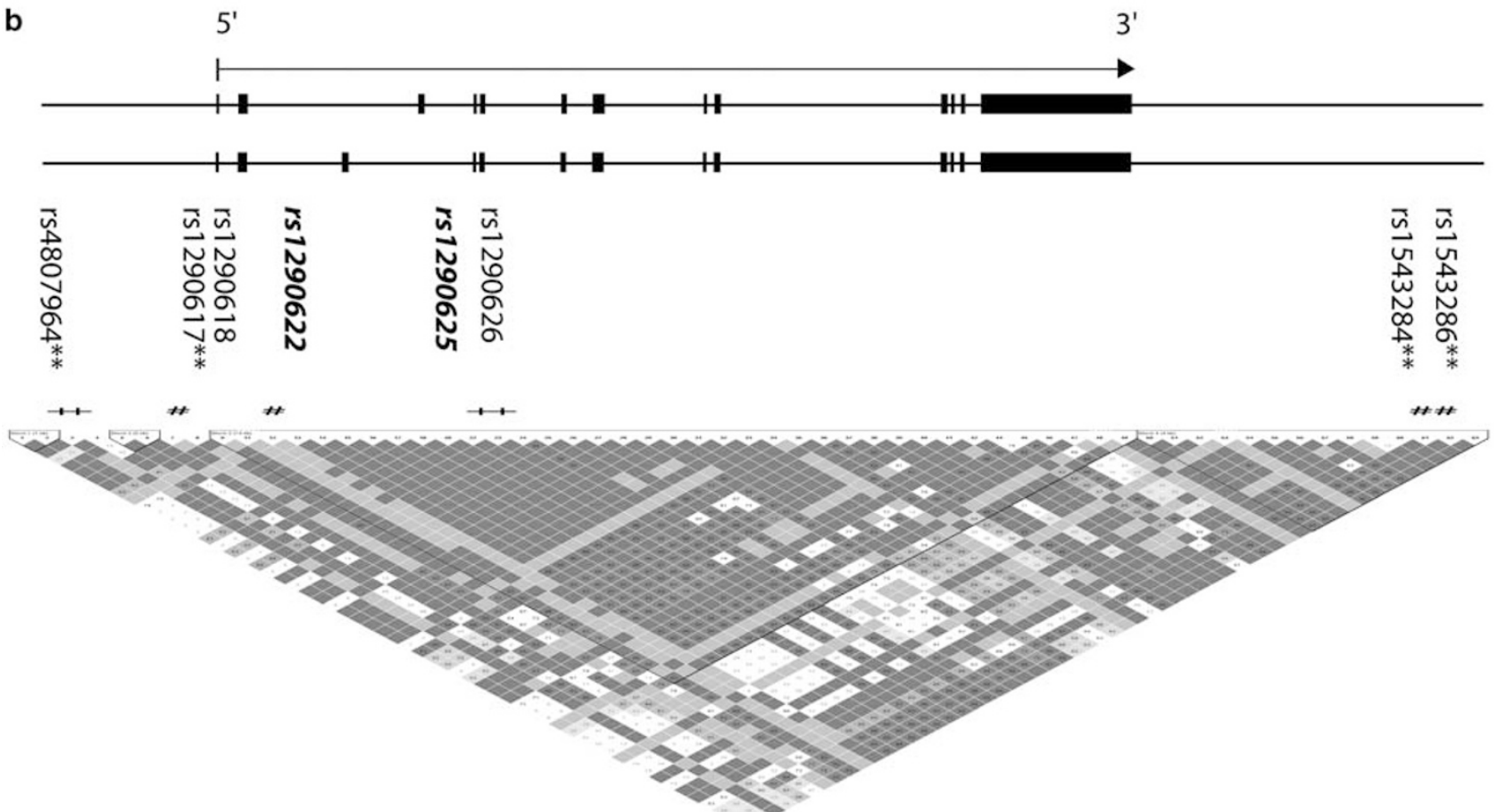

Figure 1 Overview of CYP4F2 (a) and CYP4F3 (b), isoforms a and b, respectively, showing the exons, the locations of the tag SNPs (associated tag SNPs are listed in bold italics) and the observed LD based on the HapMap information. ${ }^{* *}$ The locations of the SNPs outside the genes are not true to scale. ${ }^{*}$ rs 2108622 is a coding SNP; \# shows the position of the SNPs in the LD plot; and + shows for the SNPs that were not typed in the HapMap, the relative position of the SNPs in the LD plot.

to neutrophil recruitment and intestinal permeability will require further functional analysis. Replication in coeliac disease and expanding genetic association studies of these cytochrome genes to other inflammatory conditions should reveal whether their causative influence is true and extends beyond coeliac disease. 
Table 3 Haplotype analyses of associated SNPs in CYP4F3 (rs1290622 and rs1290625) and CYP4F2 (rs7252046 and rs3093156)

\begin{tabular}{|c|c|c|c|c|c|c|c|}
\hline \multirow[b]{2}{*}{ Gene } & \multirow[b]{2}{*}{ Haplotype } & \multicolumn{2}{|c|}{ Frequency } & \multicolumn{2}{|c|}{ Number } & \multirow[b]{2}{*}{$\chi^{2}$} & \multirow[b]{2}{*}{ P-value } \\
\hline & & Case & Control & Case & Control & & \\
\hline CYP4F3 & $\begin{array}{l}G C \\
G T \\
A C\end{array}$ & $\begin{array}{l}0.888 \\
0.054 \\
0.058\end{array}$ & $\begin{array}{l}0.883 \\
0.082 \\
0.035\end{array}$ & $\begin{array}{c}539.6 \\
33 \\
36\end{array}$ & $\begin{array}{r}632.2 \\
58.4 \\
25.4\end{array}$ & $\begin{array}{l}0.067 \\
3.882 \\
3.959\end{array}$ & $\begin{array}{l}0.7960 \\
0.0488 \\
0.0466\end{array}$ \\
\hline CYP4F2 & $\begin{array}{l}\text { TT } \\
\text { AC } \\
\text { AT } \\
\text { TC }\end{array}$ & $\begin{array}{l}0.468 \\
0.225 \\
0.238 \\
0.069\end{array}$ & $\begin{array}{l}0.417 \\
0.288 \\
0.239 \\
0.056\end{array}$ & $\begin{array}{r}289 \\
139 \\
147.4 \\
42.5\end{array}$ & $\begin{array}{c}298.3 \\
206.5 \\
171 \\
40.2\end{array}$ & $\begin{array}{l}3.572 \\
7.045 \\
0.0 \\
0.922\end{array}$ & $\begin{array}{l}0.0587 \\
0.0079 \\
0.9861 \\
0.3369\end{array}$ \\
\hline
\end{tabular}

\section{Acknowledgements}

We thank all the patients, their physicians, pathologists and the Dutch Coeliac Disease Foundation for participating in this study. We thank Jackie Senior for critically reading the manuscript. This study was supported by grants from the Netherlands Organisation for Scientific Research (Grant 912-02-028), the Dutch Digestive Diseases Foundation (Grants 97-44 and 03-06) and the Coeliac Disease Consortium, an Innovative Cluster approved by the Netherlands Genomics Initiative and partially funded by the Dutch Government (Grant BSIK03009). JDR was supported by grants from the American National Institute of Diabetes and Digestive and Kidney Diseases and the Crohn's and Colitis Foundation of America.

\section{References}

1 Macdonald TT, Monteleone G: Immunity, inflammation, and allergy in the gut. Science 2005; 307: 1920-1925.

2 Babron MC, Nilsson S, Adamovic S et al: Meta and pooled analysis of European coeliac disease data. Eur J Hum Genet 2003; 11: 828834

3 Van Belzen MJ, Meijer JW, Sandkuijl LA et al: A major non-HLA locus in celiac disease maps to chromosome 19. Gastroenterology 2003; 125: 1032-1041.

4 Rioux JD, Silverberg MS, Daly MJ et al: Genomewide search in Canadian families with inflammatory bowel disease reveals two novel susceptibility loci. Am J Hum Genet 2000; 66: 1863-1870.

5 van Heel DA, Satsangi J, Carey AH, Jewell DP: Inflammatory bowel disease: progress toward a gene. Can J Gastroenterol 2000; 14: 207-218.

6 Schreiber S, Rosenstiel P, Albrecht M, Hampe J, Krawczak M: Genetics of Crohn disease, an archetypal inflammatory barrier disease. Nat Rev Genet 2005; 6: 376-388.

7 Van Heel DA, Fisher SA, Kirby A, Daly MJ, Rioux JD, Lewis CM: Inflammatory bowel disease susceptibility loci defined by genome scan meta-analysis of 1952 affected relative pairs. Hum Mol Genet 2004; 13: 763-770.

8 Ueda H, Howson JM, Esposito L et al: Association of the T-cell regulatory gene CTLA4 with susceptibility to autoimmune disease. Nature 2003; 423: 506-511.

9 Begovich AB, Carlton VE, Honigberg LA et al: A missense singlenucleotide polymorphism in a gene encoding a protein tyrosine phosphatase (PTPN22) is associated with rheumatoid arthritis. Am J Hum Genet 2004; 75: 330-337.

10 Bottini N, Musumeci L, Alonso A et al: A functional variant of lymphoid tyrosine phosphatase is associated with type I diabetes. Nat Genet 2004; 36: 337-338.

11 Zhernakova A, Eerligh P, Wijmenga C, Barrera P, Roep BO, Koeleman BP: Differential association of the PTPN22 coding variant with autoimmune diseases in a Dutch population. Genes Immun 2005; 6: 459-461.

12 Cottone M, Marrone C, Casa A et al: Familial occurrence of inflammatory bowel disease in celiac disease. Inflamm Bowel Dis 2003; 9: 321-323.

13 Schedel J, Rockmann F, Bongartz T, Woenckhaus M, Scholmerich J, Kullmann F: Association of Crohn's disease and latent celiac disease: a case report and review of the literature. Int J Colorectal Dis 2005; 20: 376-380.

14 Tursi A, Giorgetti GM, Brandimarte G, Elisei W: High prevalence of celiac disease among patients affected by Crohn's disease. Inflamm Bowel Dis 2005; 11: 662-666.

15 Yang A, Chen Y, Scherl E, Neugut AI, Bhagat G, Green PH: Inflammatory bowel disease in patients with celiac disease. Inflamm Bowel Dis 2005; 11: 528-532.

16 Rioux JD, Daly MJ, Silverberg MS et al: Genetic variation in the 5 q31 cytokine gene cluster confers susceptibility to Crohn disease. Nat Genet 2001; 29: 223-228.

17 Monsuur AJ, Bakker PI, Alizadeh BZ et al: Myosin IXB variant increases the risk of celiac disease and points toward a primary intestinal barrier defect. Nat Genet 2005; 37: 1341-1344.

18 Gabriel SB, Schaffner SF, Nguyen $\mathrm{H}$ et al: The structure of haplotype blocks in the human genome. Science 2002; 296: 2225-2229.

19 Barrett JC, Fry B, Maller J, Daly MJ: Haploview: analysis and visualization of LD and haplotype maps. Bioinformatics 2005; 21: 263-265.

20 Peltekova VD, Wintle RF, Rubin LA et al: Functional variants of OCTN cation transporter genes are associated with Crohn disease. Nat Genet 2004; 36: 471-475.

21 Tello-Ruiz MK, Curley C, DelMonte T et al: Haplotype-based association analysis of 56 functional candidate genes in the IBD6 locus on chromosome 19. Eur J Hum Genet 2006; 14: 780-790.

22 Matter K, Balda MS: Signalling to and from tight junctions. Nat Rev Mol Cell Biol 2003; 4: 225-236.

23 Mankertz J, Tavalali S, Schmitz $\mathrm{H}$ et al: Expression from the human occludin promoter is affected by tumor necrosis factor alpha and interferon gamma. J Cell Sci 2000; 113 (Part 11): 2085 2090.

24 Diosdado B, van Bakel H, Strengman E et al: A genomics view on celiac disease points to enhanced neutrophil recruitment and barrier impairment, 2005, (submitted).

25 Helaakoski T, Annunen P, Vuori K, MacNeil IA, Pihlajaniemi T, Kivirikko KI: Cloning, baculovirus expression, and characterization of a second mouse prolyl 4-hydroxylase alpha-subunit isoform: formation of an alpha 2 beta 2 tetramer with the protein disulfide-isomerase/beta subunit. Proc Natl Acad Sci USA 1995; 92: 4427-4431.

26 Christmas P, Jones JP, Patten CJ et al: Alternative splicing determines the function of CYP4F3 by switching substrate specificity. J Biol Chem 2001; 276: 38166-38172. 
27 Christmas P, Ursino SR, Fox JW, Soberman RJ: Expression of the CYP4F3 gene. Tissue-specific splicing and alternative promoters generate high and low $\mathrm{K}(\mathrm{m})$ forms of leukotriene $\mathrm{B}(4)$ omegahydroxylase. J Biol Chem 1999; 274: 21191-21199.

28 Kikuta Y, Kusunose E, Endo K et al: A novel form of cytochrome $P$ 450 family 4 in human polymorphonuclear leukocytes. cDNA cloning and expression of leukotriene B4 omega-hydroxylase. J Biol Chem 1993; 268: 9376-9380.

29 Kikuta Y, Miyauchi Y, Kusunose E, Kusunose M: Expression and molecular cloning of human liver leukotriene B4 omega-hydroxylase (CYP4F2) gene. DNA Cell Biol 1999; 18: 723-730.

30 Greene TA, Powell P, Nzerem C, Shapiro MJ, Shapiro VS: Cloning and characterization of ALX, an adaptor downstream of CD28. J Biol Chem 2003; 278: 45128-45134.

31 Oda T, Muramatsu MA, Isogai T, Masuho Y, Asano S, Yamashita T: HSH2: a novel SH2 domain-containing adapter protein involved in tyrosine kinase signaling in hematopoietic cells. Biochem Biophys Res Commun 2001; 288: 1078-1086.

32 Altare F, Durandy A, Lammas D et al: Impairment of mycobacterial immunity in human interleukin-12 receptor deficiency. Science 1998; 280: 1432-1435.

33 Chua AO, Chizzonite R, Desai BB et al: Expression cloning of a human IL-12 receptor component. A new member of the cytokine receptor superfamily with strong homology to gp130. J Immunol 1994; 153: 128-136.

34 Watanabe T, Kitani A, Murray PJ, Strober W: NOD2 is a negative regulator of Toll-like receptor 2-mediated $\mathrm{T}$ helper type 1 responses. Nat Immunol 2004; 5: 800-808.

35 Arunachalam B, Phan UT, Geuze HJ, Cresswell P: Enzymatic reduction of disulfide bonds in lysosomes: characterization of a gamma-interferon-inducible lysosomal thiol reductase (GILT). Proc Natl Acad Sci USA 2000; 97: 745-750.

Supplementary Information accompanies the paper on European Journal of Human Genetics website (http://www.nature.com/ejhg) 